\title{
Costs of Biopsy and Complications in Patients with Lung Cancer
}

This article was published in the following Dove Press journal:

ClinicoEconomics and Outcomes Research

\author{
Yu-Wen Chiu' \\ Yu-Hsiang Kao' \\ Michael J Simoff ${ }^{2}$ \\ David E Ost ${ }^{3}$ \\ Oliver Wagner ${ }^{4}$ \\ James Lavin (1D ${ }^{4}$ \\ Richard A Culbertson ${ }^{\prime}$ \\ Dean G Smith (D) \\ 'Health Policy \& Systems Management, \\ School of Public Health, Louisiana State \\ University Health Sciences Center, New \\ Orleans, Louisiana, USA; ${ }^{2}$ Pulmonary and \\ Critical Care Medicine, Henry Ford \\ Hospital, Detroit, Michigan, USA; \\ ${ }^{3}$ Department of Pulmonology, University \\ of Texas MD Anderson Cancer Center, \\ Houston, Texas, USA; ${ }^{4}$ Intuitive Surgical, \\ Sunnyvale, California, USA
}

Correspondence: Dean G Smith LSU Health Sciences Center - New Orleans, School of Public Health, 2020 Gravier St., New Orleans, LA, 70II2, USA

Email dgsmith@Isuhsc.edu
Purpose: To describe the distribution of diagnostic procedures, rates of complications, and total cost of biopsies for patients with lung cancer.

Patients and Methods: Observational study using data from IBM Marketscan ${ }^{\circledR}$ Databases for continuously insured adult patients with a primary lung cancer diagnosis and treatment between July 2013 and June 2017. Costs of lung cancer diagnosis covered 6 months prior to index biopsy through treatment. Costs of chest CT scans, biopsy, and post-procedural complications were estimated from total payments. Costs of biopsies incidental to inpatient admissions were estimated by comparable outpatient biopsies.

Results: The database included 22,870 patients who had a total of 37,160 biopsies, of which 16,009 (43.1\%) were percutaneous, 14,997 (40.4\%) bronchoscopic, 4072 (11.0\%) surgical and 2082 (5.6\%) mediastinoscopic. Multiple biopsies were performed on $41.9 \%$ of patients. The most common complications among patients receiving only one type of biopsy were pneumothorax (1304 patients, 8.4\%), bleeding (744 patients, 4.8\%) and intubation (400 patients, 2.6\%). However, most complications did not require interventions that would add to costs. Median total costs were highest for inpatient surgical biopsies $(\$ 29,988)$ and lowest for outpatient percutaneous biopsies (\$1028). Repeat biopsies of the same type increased costs by $40-80 \%$. Complications account for $13 \%$ of total costs.

Conclusion: Costs of biopsies to confirm lung cancer diagnosis vary substantially by type of biopsy and setting. Multiple biopsies, inpatient procedures and complications result in higher costs.

Keywords: cancer, diagnosis, economics, frequency

\section{Introduction}

Lung cancer is the leading cause of cancer-related deaths in both the United States and the world, causing more deaths than colorectal, breast, and prostate cancers combined. An estimated 154,050 Americans died of lung cancer in 2018, accounting for about $26 \%$ of all cancer deaths in the United States. ${ }^{1}$ The overall 5 -year survival rate for patients with lung cancer is poor relative to the other major cancers (18.6\%, vs $64.5 \%$ colorectal, $89.7 \%$ breast and $98.2 \%$ prostate). Survival rates vary from $53.6 \%$ for patients with localized disease, to $29.7 \%$ for patients with regionally invasive disease (local lymph nodal extension), and $4.7 \%$ for people with metastatic disease. $^{2}$

Due to the lack of symptoms in the early stages of disease, most lung cancers $(84 \%)$ are diagnosed late with the regional or distant extension of the disease, limiting treatment options and impacting survival. ${ }^{2}$ A variety of imaging technologies are used to identify suspicious lesions, but the discriminatory capability of 
existing imaging technologies for diagnosis does not exist. Early detection of lung cancer offers the potential to modify the entire landscape of health services offered, perhaps at substantially lower costs to patients and health plans.

Tissue biopsy procedures play an essential role in the clinical pathway for the diagnosis of lung cancer. Guidelines, including those of the American College of Chest Physicians and National Comprehensive Cancer Network, are available to assess options that are best suited to different clinical scenarios. ${ }^{3,4}$ With the advent of new clinical assays to test for both germline and somatic alterations that are prognostic and/or predictive of disease outcome, toxicity or treatment, biopsy yield and specimen quality are critical to determine whether patients are candidates for specific therapies. ${ }^{5}$ Inconclusive diagnostic procedures increase the need for repeat biopsy, extend the time to treatment, add cost burden and undue psychological stress for patients and their families.

The objective of this paper is to describe the distribution of diagnostic procedures, rates of complications, and total cost of procedures related to lung cancer diagnosis using data from a US administrative claims database.

\section{Patients and Methods Database}

This observational study utilized data from both the IBM Marketscan ${ }^{\circledR}$ Commercial Claims and Encounters and Medicare Supplemental Databases. ${ }^{6}$ The Marketscan ${ }^{\circledR}$ Databases are constructed from privately insured, paid, medical and prescription drug claims contributed by employers and health plans who have business relationships with IBM Watson Health. Collectively, the data are incorporated from approximately 350 payers, including commercial insurance companies, Blue Cross and Blue Shield plans, and third-party administrators and include approximately 62 million covered lives. Each contributor's database is constructed by collecting raw data from the participating payer(s). These raw data are service-level adjudicated paid claims and capitated encounters containing both inpatient and outpatient services. As the database is fully de-identified and compliant with HIPAA regulations this study was exempted from Institutional Review Board approval. ${ }^{6}$

\section{Study Population}

The target population included patients aged 18 years and older who had one primary lung cancer diagnosis between
July 1, 2013 and June 30, 2017 and had treatment after the diagnosis of lung cancer reported on medical claims. The diagnosis of lung cancer was based on the use of identified codes from the International Classification of Diseases, Ninth Revision (ICD-9-CM 162.x) and the International Classification of Diseases, Tenth Revision (ICD-10 C33, C34.xx) as both systems were used during the study period. Treatment was defined by identifying Current Procedural Terminology (CPT) and/or ICD-9-CM or ICD-10-CM procedure codes for surgery, ablation, radiation therapy or chemotherapy, and the National Drug Code (NDC) for therapeutic agents used in the treatment of lung cancer in relation to a procedure. Patients without evidence of health plan enrollment 6 months prior to and after their diagnosis and those who did not receive any lung cancer treatment after diagnosis were excluded from the focused study population (Figure 1).

\section{Study Variables}

We extracted the following information from the IBM MarketScan ${ }^{\circledR}$ database: date of diagnosis, type and number of procedures, cancer history, comorbidity, age, gender, and type of insurance plan. Comorbidity was calculated using Charlson comorbidity index score. ${ }^{7,8}$ Having only administrative data, other characteristics such as disease stage are unavailable. Procedures were stratified into four categories: CT-guided percutaneous biopsy, bronchoscopy, surgical biopsy, and mediastinoscopy. Chest CT scans were identified with CPT codes $(71250,71260$, or 71270). Biopsy-related complications captured were pneumothorax, prolonged air leak, hemorrhage, post-treatment change to intubated/mechanical ventilation, mediastinitis, pneumonia, empyema and abscess of lung. ICD-9-CM or ICD-10-CM diagnosis codes were used to identify qualifying post-procedural complications (Supplement Information). Complications must have occurred within a day immediately following the biopsy procedure to be considered biopsy-related, except for prolonged air leak and abscess of the lung. For these complications, the time interval was 5 days after the biopsy date. To derive complications and costs associated with each particular type of biopsy, we excluded patients who received more than one type of biopsy from the analysis. In addition, thoracotomy; with diagnostic wedge resection followed by anatomic lung resection (CPT code 32668) and thoracoscopy, surgical; with diagnostic wedge resection followed by anatomic lung resection (CPT code 32507) were excluded from the complications analysis, since we are unable to determine if 


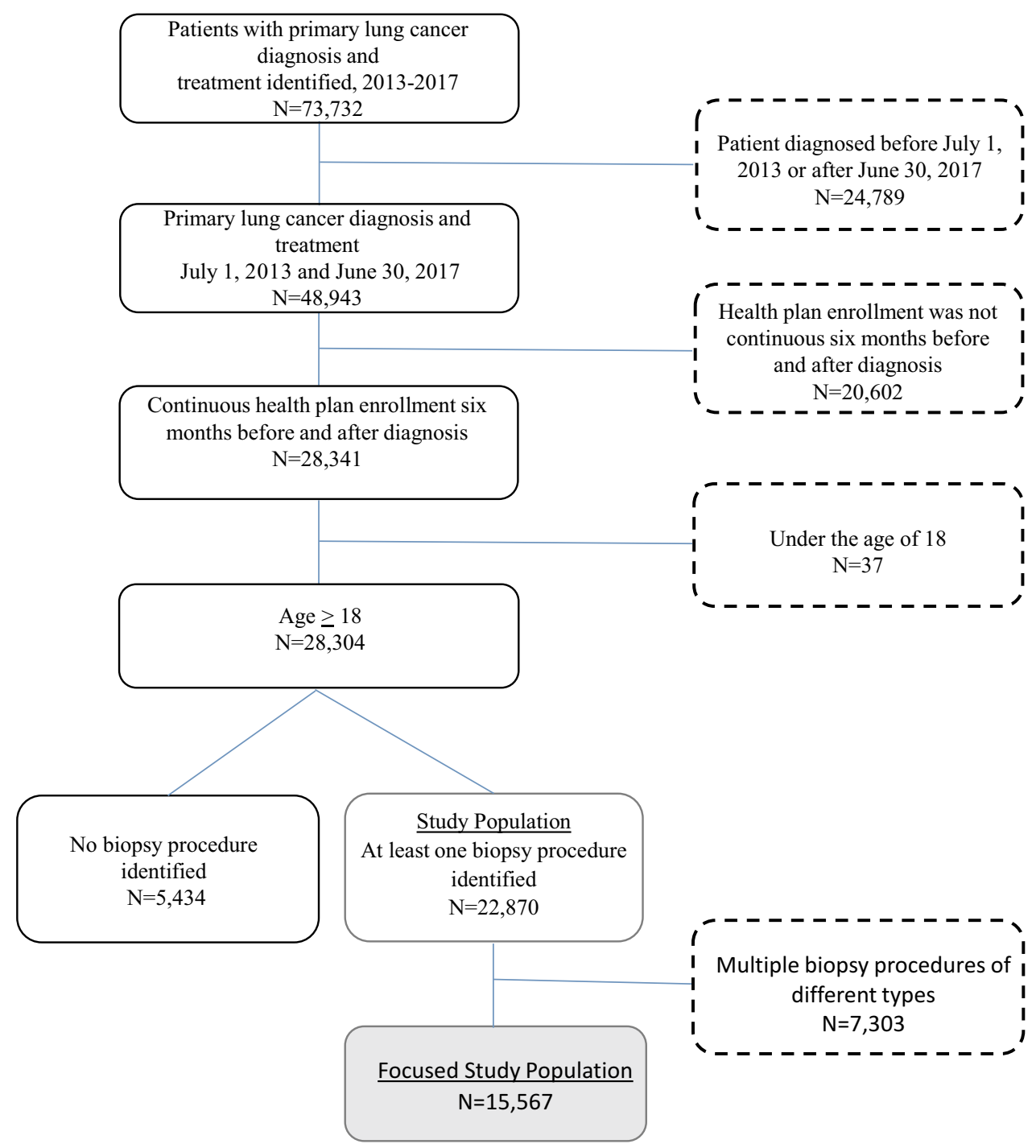

Figure I Lung cancer patient characteristics by biopsy status.

the complication was from the biopsy or a surgical treatment.

\section{Cost Analysis}

Total costs associated with a lung cancer diagnosis from the combined payer and patient perspectives beginning 6 months prior to index date through treatment date were included in the analyses. Costs of chest CT scans, biopsy, and post-biopsy complications were estimated from total payments, as reported in the claims data. Costs for services provided under capitated arrangements were estimated using payment proxies that were computed based on average paid claims at the procedure level in the claims data. Costs of biopsy included both procedure and physician payment in the outpatient setting. Biopsy performed in the inpatient setting included all costs incurred to the payer during the entire hospital stay, including complication costs. Costs were normalized to 2017 US dollars using the US Bureau of Labor Statistics' Consumer Price Index Medical Care Component.

Costs associated with outpatient biopsies and inpatient biopsies where the biopsy occurs within the first 2 days of hospitalization are simply the reported payments. Biopsies that occur on the third day or later in a hospitalization are counted in this analysis, but the cost associated with the biopsy requires careful treatment. Attributing the entire payment for a hospitalization with what might be considered to be an incidental biopsy would overstate the true cost of the biopsy. Likewise, omitting any payment would understate the true cost. As a compromise, the costs of inpatient biopsies that occur after day 3 are estimated by 
the average cost of the same type of biopsy occurring in an outpatient setting.

All analyses were conducted using the statistical software SAS, version 9.4 (SAS Institute Inc.).

\section{Results}

A total of 73,732 patients with a primary diagnosis and evidence of treatment for lung cancer in their records between January 1, 2013 and December 31, 2017 were identified in the IBM MarketScan ${ }^{\circledR}$ database (Figure 1). Of these, 24,789 patients were diagnosed before July 1, 2013 or after June 30, 2017 and were excluded from further analyses. An additional, 20,502 did not have evidence of continuous health insurance enrollment. Only 37 patients were ineligible due to age limits, leaving a total of 28,304 patients for the final analytical sample. The study population includes $81 \%$ of patients $(\mathrm{N}=22,870)$ with evidence of one or more biopsies in their claims data. Those patients with no evidence of biopsy (19.2\%) tended to be younger than the overall population average, have higher Charlson comorbidity scores, have a history of cancer (both with and without evidence of metastasis), have no evidence of CT scans, and a greater percentage with the period from diagnosis to treatment exceeding 6 months (Table 1).

Fifty-eight percent of patients $(\mathrm{N}=13,270)$ underwent only one biopsy procedure of which $48.3 \%$ were percutaneous, $41.2 \%$ were bronchoscopic, $9.4 \%$ were surgical and $1.1 \%$ were mediastinoscopy (Table 2). Another 27.7\% required two, and the remaining $14.2 \%$ required three or more biopsy procedures. For the $41.9 \%$ of patients with more than one biopsy procedure of the same type, the overall percentage and distribution of procedures remained similar with slight increases in the frequency of surgical and mediastinoscopy procedures. Viewing these data by the type of procedure shows that $33.8 \%$ of patients had one or more percutaneous biopsies, $28.0 \%$ had one or more bronchoscopic biopsies, $5.5 \%$ had one or more surgical biopsies and less than $1 \%$ had one or more mediastinoscopies. Approximately $32 \%$ had multiple biopsies of different types. (Supplemental Information)

In order to assess complication rates by biopsy type, we examined only patients receiving one or more biopsy procedures of the same type, resulting in a focused study population of 15,567 patients. Complication rates were highest among those patients receiving percutaneous biopsy, followed by bronchoscopy, mediastinoscopy and surgery (Table 3). Infection among patients undergoing surgical biopsy or mediastinoscopy was relatively rare.
There were no cases of infection among those undergoing percutaneous or bronchoscopic biopsy procedures.

Median cost (and interquartile range) of single and multiple biopsies, occurring in outpatient or inpatient settings, or both for some multiple biopsies are presented in Table 4 . Median costs, including the biopsy, CT scan, and complications, were highest for inpatient surgical biopsies $(\$ 29,988)$ and lowest for outpatient percutaneous biopsies (\$1028). Repeat biopsy procedures of the same type were most common in patients who had a percutaneous or bronchoscopic biopsy. Repeat biopsies of the same type increased costs by $40-80 \%$. The mean costs, irrespective of biopsy type, were $\$ 11,350, \$ 23,651, \$ 29,800$, and $\$ 42,520$ for one, two, three, or four or more biopsy procedures, respectively.

Median total costs varied substantially by setting. Over one-quarter (29\%) of all biopsies were performed as inpatient diagnostic procedures. Inpatient biopsies were costlier than outpatient biopsies by a factor of 8 (single mediastinoscopy) to 20 (single surgical). Inpatient biopsies accounted for $81 \%$ of total costs.

Rates of complications varied substantially by type of procedures, though only a fraction of complications required further interventions that resulted in additional costs. Incremental costs associated with complications averaged $\$ 667$, which corresponds to $13 \%$ of total costs. Complication costs were $11 \%$ of costs of patients receiving only one biopsy and $20 \%$ for patients receiving 2 or more biopsies.

\section{Discussion}

Nearly $42 \%$ of the study population underwent two or more biopsy procedures prior to the initiation of treatment, adding as much as $40-80 \%$ to the per patient median cost for percutaneous and bronchoscopic procedures. Bronchoscopic and percutaneous biopsies accounted for approximately $90 \%$ of the procedures while surgery accounted for $10 \%$, which is similar to the $11.4 \%$ reported by Vyas in $2013 .{ }^{9}$ Using the same Marketscan ${ }^{\circledR}$ database, Zhang et al analyzed the frequency of biopsy procedures in a lung cancer patient population for $2013-15,{ }^{10}$ and Shinde et al analyzed the frequency of biopsy procedures in a lung cancer patient population using erlotinib or crizotinib for 2009-2012. ${ }^{11}$ Zhang et al used the same continuous enrollment criteria of 6 months prior to and 6 months following biopsy and did not examine costs. Shinde et al selected patients based on an index claim for the use of either erlotinib or crizotinib, and continuous enrollment 12 months prior to and 12 months following biopsy. Even with these differences, our findings in terms of the number of additional procedures are quite similar to both studies. 
Table I Lung Cancer Patient Characteristics by Biopsy Status

\begin{tabular}{|c|c|c|c|c|c|c|c|}
\hline \multirow[t]{2}{*}{ Variable } & \multirow[b]{2}{*}{$\mathbf{N}$} & \multirow[b]{2}{*}{$\%$} & \multicolumn{2}{|c|}{ No Biopsy } & \multicolumn{2}{|c|}{ Received Biopsies } & \multirow[t]{2}{*}{$P$ value } \\
\hline & & & $\mathbf{n}$ & $\%$ & $\mathbf{n}$ & $\%$ & \\
\hline Total & 28,304 & 100.0 & 5434 & 19.2 & 22,870 & 80.8 & \\
\hline Age at diagnosis & & & & & & & $<0.001$ \\
\hline $18-44$ & 866 & 3.1 & 226 & 4.2 & 640 & 2.8 & \\
\hline $45-54$ & 3442 & 12.2 & 845 & 15.6 & 2597 & 11.4 & \\
\hline $55-64$ & 10,234 & 36.2 & 2016 & 37.1 & 8218 & 35.9 & \\
\hline $65-74$ & 7375 & 26.1 & $129 \mid$ & 23.8 & 6084 & 26.6 & \\
\hline $75-84$ & 5287 & 18.7 & 828 & 15.2 & 4459 & 19.5 & \\
\hline $85+$ & 1100 & 3.9 & 228 & 4.2 & 872 & 3.8 & \\
\hline Gender & & & & & & & $<0.01$ \\
\hline Male & 13,750 & 48.6 & 2553 & 47.0 & $1 \mathrm{I}, 197$ & 49.0 & \\
\hline Female & 14,554 & 51.4 & 2881 & 53.0 & 11,673 & 51.0 & \\
\hline Type of insurance & & & & & & & 0.0945 \\
\hline EPO & 225 & 0.8 & 39 & 0.7 & 186 & 0.8 & \\
\hline HMO & 2573 & 9.1 & 521 & 9.6 & 2052 & 9.0 & \\
\hline POS & 1836 & 6.5 & 354 & 6.5 & 1482 & 6.5 & \\
\hline PPO & 14,386 & 50.8 & 2816 & 51.8 & $1 \mathrm{I}, 570$ & 50.6 & \\
\hline Other & 9284 & 32.8 & 1704 & 31.4 & 7580 & 33.1 & \\
\hline Year of diagnosis & & & & & & & $<0.001$ \\
\hline 2013 & 5518 & 19.5 & 1146 & 21.1 & 4372 & 19.1 & \\
\hline 2014 & 8444 & 29.8 & 1680 & 30.9 & 6764 & 29.6 & \\
\hline 2015 & 6568 & 23.2 & 1209 & 22.3 & 5359 & 23.4 & \\
\hline 2016 & 5430 & 19.2 & 1003 & 18.5 & 4427 & 19.4 & \\
\hline 2017 & 2344 & 8.3 & 396 & 7.3 & 1948 & 8.5 & \\
\hline Charlson comorbidities index* & & & & & & & $<0.001$ \\
\hline 0 & 6056 & 21.4 & 1033 & 19.0 & 5023 & 22.0 & \\
\hline 1 & 6629 & 23.4 & 817 & 15.0 & 5812 & 25.4 & \\
\hline $2+$ & 15,619 & 55.2 & 3584 & 66.0 & 12,035 & 52.6 & \\
\hline Cancer history* & & & & & & & $<0.001$ \\
\hline No & 20,597 & 72.8 & 3105 & 57.1 & 17,492 & 76.5 & \\
\hline Yes (No metastatic record) & 5883 & 20.8 & 1594 & 29.3 & 4289 & 18.8 & \\
\hline Yes (Metastasis to other organs) & 998 & 3.5 & 475 & 8.7 & 523 & 2.3 & \\
\hline Yes (Metastasis to lung) & 826 & 2.9 & 260 & 4.8 & 566 & 2.5 & \\
\hline Total CT scans* & & & & & & & $<0.001$ \\
\hline 0 & 6878 & 24.3 & 2047 & 37.7 & 4831 & 21.1 & \\
\hline 1 & 18,442 & 65.2 & 2903 & 53.4 & 15,539 & 67.9 & \\
\hline 2 & 2615 & 9.2 & 402 & 7.4 & 2213 & 9.7 & \\
\hline $3+$ & 369 & 1.3 & 82 & 1.5 & 287 & 1.3 & \\
\hline Time from diagnosis to treatment & & & & & & & $<0.001$ \\
\hline Same day & 2531 & 8.9 & 608 & 11.2 & 1923 & 8.4 & \\
\hline Within 6 months & 23,811 & 84.1 & 4160 & 76.6 & $|9,65|$ & 85.9 & \\
\hline More than 6 months & 1962 & 6.9 & 666 & 12.3 & 1296 & 5.7 & \\
\hline
\end{tabular}

Notes: Others include comprehensive, Medicare wrap-around, consumer driven, and high deductible health plans, and missing values. Asterisk*Clinical characteristics were identified up to 6 months prior to lung cancer diagnosis.

Abbreviations: Type of insurance: EPO, exclusive provider organization; HMO, health maintenance organization; POS, point of service; PPO, preferred provider organization. 
Table 2 Distribution of Biopsies by Frequency

\begin{tabular}{|l|l|l|l|l|l|l|l|l|l|l|}
\hline & \multicolumn{2}{l}{ Patients } & \multicolumn{2}{l|}{ Percutaneous } & \multicolumn{2}{l|}{ Bronchoscopy } & \multicolumn{2}{l|}{ Surgical } & \multicolumn{2}{l|}{ Mediastinoscopy } \\
\hline Biopsy Procedures & $\mathbf{n}$ & $\%$ & $\mathbf{n}$ & $\%$ & $\mathbf{n}$ & $\%$ & $\mathbf{n}$ & $\%$ & $\mathbf{n}$ \\
\hline I procedure & 13,270 & 58.0 & 6410 & 48.3 & 5468 & 41.2 & 1244 & 9.4 & 148 & 1.1 \\
2 procedures & 6342 & 27.7 & 5124 & 40.4 & 5264 & 41.5 & 1601 & 12.6 & 695 & 5.5 \\
3 procedures & 2266 & 9.9 & 2641 & 38.9 & 2629 & 38.7 & 798 & 11.7 & 730 & 10.7 \\
$\geq 4$ procedures & 992 & 4.3 & 1834 & 41.6 & 1636 & 37.1 & 429 & 9.7 & 509 & 11.6 \\
Overall & 22,870 & 100.0 & 16,009 & 43.1 & 14,997 & 40.4 & 4072 & 11.0 & 2082 & 5.6 \\
\hline
\end{tabular}

Note: Average procedures per patient: 1.6 (37,160 biopsies divided by 22,870 patients).

Complication rates following biopsy procedures likely depend upon a variety of factors including patient characteristics (eg, comorbidities, location of lesions), procedural processes (eg, puncture time length), the length of time following the procedure to assess a complication and the type of study (eg, case series vs clinical trial). In the recent literature, pneumothorax with transthoracic needle aspiration remains the most frequently reported complication, with rates ranging from $15 \%$ to $25 \%$, of which $6-11 \%$ of those patients requiring a chest tube for management. ${ }^{12,13} \mathrm{~A}$ recent meta-analysis by Heerink et al reported a pooled pneumothorax complication rate of $25.3 \%$ and $18.8 \%$ for a core biopsy and fine-needle aspiration, respectively. However, pneumothorax complication rates varied widely from $8.4 \%$ to $53.5 \%$. The pooled estimate for bleeding complications was $18 \%$ and $6.4 \%$ for a core biopsy and fine-needle aspiration, respectively. Bleeding complication rates showed even more variability ranging from $2.9 \%$ to $54.4 \% .{ }^{14}$ In our study, the complication rates for pneumothorax and hemorrhage following percutaneous biopsy were $14.64 \%$ and $2.2 \%$, respectively. One possible explanation for the lower rates observed in our study is the exclusion of 7303 patients who received multiple biopsy procedures of different approaches. The inclusion of this subset into complication rate estimates is a subject for further study.

To ensure that we accurately achieve the objective of our study to evaluate the total costs, we included specific procedure codes and limited the window of observation to ensure that our study complication rates were similar to other published findings; thus validating complication rates and ensuring that interventions to patient clinical pathways which would impact costs. As such, the complication rate associated with bronchoscopic procedures is considerably lower than the complication rate associated with percutaneous procedures. In a meta-analysis of guided bronchoscopy for the evaluation of the pulmonary nodule, Memoli et al reported a pneumothorax rate of approximately $1.5 \%$ and no events of bleeding. ${ }^{15}$ In a multi-center study of consecutive patients undergoing bronchoscopy, rates of pneumothorax and hemorrhage were $1.7 \%$ and $0.1 \%$, respectively. ${ }^{16}$ Our results show comparable findings for pneumothorax but higher rates for hemorrhage or bleeding given the varying degree of hemorrhage and the subsequent need for blood transfusion. ${ }^{17}$ While our study finds a higher rate of hemorrhage, we also find that these patients did not require an intervention of transfusion; indicating that these bleed types were of minor complexity and resolved on their own. Furthermore, published complication rates for surgical biopsy are approximately 5\%, inclusive of air leaks and pneumonia. ${ }^{3}$ In our study, approximately $2 \%$ of patients undergoing surgical biopsy experienced air leaks and pneumonia, lower, but comparable to previously published findings.

Lung cancer has been estimated to cost approximately $\$ 60,000$ in the first year after diagnosis and approximately $\$ 8000$ per year thereafter. Costs during the last year of life may exceed $\$ 90,000 .^{18,19}$ There is little information on the costs of lung cancer from nodule biopsy to cancer therapy. In this study, repeat biopsies increased costs by $40-80 \%$. Lokhandwala and colleagues estimated the total diagnostic cost for patients from an abnormal chest CT scan to assessment for lung cancer diagnosis using Medicare data and reported a combined value of $\$ 38.3$ million in their final sample, of which $43.1 \%$ was accounted for by patients receiving biopsy procedures without lung cancer. ${ }^{20}$

Huo et al estimated complication costs following biopsy procedures and reported mean incremental costs of $\$ 6320$ for minor complications to $\$ 56,845$ for major complications. ${ }^{21}$ However, their analysis included costs for complications for one full year, rather than an episodic analysis of 1 day to 5 days post procedure, and also included surgical treatment within the surgical biopsy 


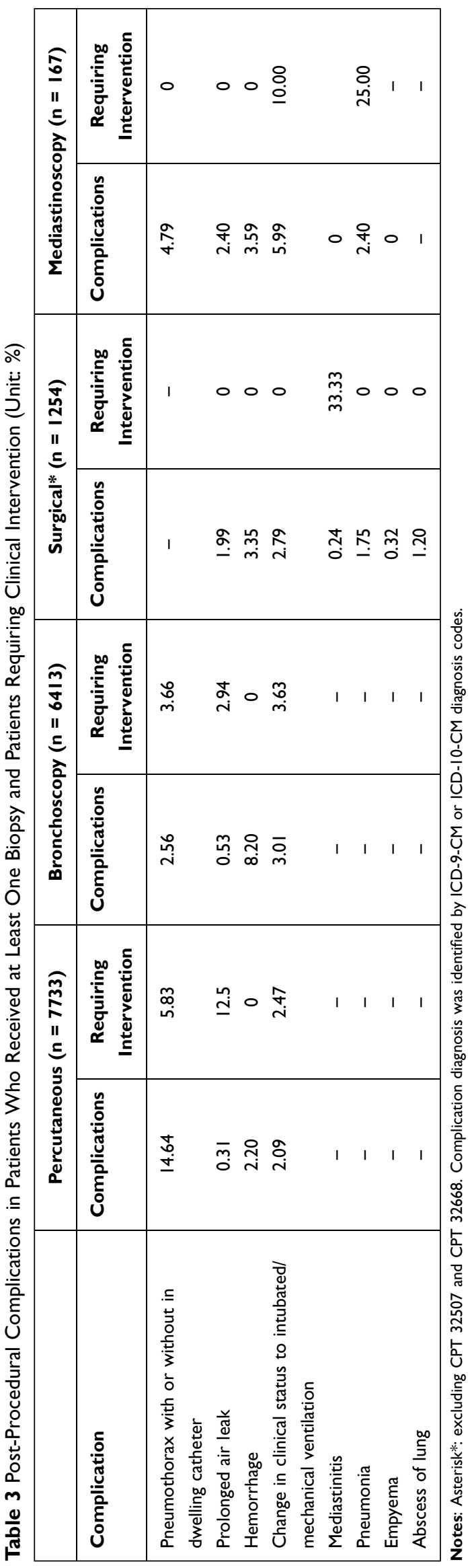

definition. Our finding of average complication costs was $\$ 667,13 \%$ of the overall median costs, suggesting lower cost associated with complications. Multiple biopsies create additional costs due to the procedure itself, as well as additional costs associated with complications associated with the second, third or fourth biopsy. We attribute all of the costs of complications to the complication directly. A case could be made for attributing some of the costs of complications to having multiple biopsies, making the $13 \%$ value an overestimate.

Our analysis suggests that the key drivers of the costs of biopsies are repeat procedures and the procedure setting. The lower impact of complication costs in this study may also be attributable to the exclusion of patients with multiple biopsy types, though some portion of complication costs may be attributable to the process of multiple biopsies. Additionally, patients were only counted once for the rates of different types of complication even though there may have been multiple reports of the same type of complication. Complications were rarely associated with treatment, identified by a unique procedure code within the timing conditions of this study. The impact of episodic MS-DRG bundling on the costs of complications is unknown.

\section{Limitations}

As with any data source, IBM MarketScan ${ }^{\circledR}$ has limitations. Claims data come mostly from large employers providing coverage for their employees and dependents. The study population does not include persons who are uninsured, publically insured other than by Medicare, or persons without continuous enrollment. Unique to the US, nearly $30 \%$ of those diagnosed with lung cancer in these data did not have evidence of continuous health insurance enrollment, which is typically associated with a person's changing employment status or employer's changing insurance. The study likely disproportionately excludes persons who have low incomes. Thus, the results may not be generalizable to the US population as a whole, nor to other jurisdictions where the entire population is insured.

Claims data are focused on administrative rather than clinical information. Clinical information that may be very relevant in analyses of complications and costs, such as the stage of disease upon diagnosis, are not included in claims data. For this discussion of lung cancer, the absence of additional clinical information is an important limitation. 
Table 4 Median Cost of Biopsy Procedure and Interquartile Range (IQR) by Type, Number of Procedures and Care Setting, Inclusive of Complications Cost

\begin{tabular}{|c|c|c|c|c|}
\hline $\begin{array}{l}\text { Procedures/ } \\
\text { Location }\end{array}$ & $\begin{array}{l}\text { Percutaneous } \\
(n=7733)\end{array}$ & $\begin{array}{l}\text { Surgical } \\
(n=1254)\end{array}$ & $\begin{array}{c}\text { Bronchoscopy } \\
(n=64 \mid 3)\end{array}$ & $\begin{array}{c}\text { Mediastinoscopy } \\
(\mathrm{n}=167)\end{array}$ \\
\hline $\begin{array}{l}\text { Procedure } \\
\text { Outpatient }\end{array}$ & $\begin{array}{c}n=5321 \\
\$ 1028.52 \\
{[1543.01]}\end{array}$ & $\begin{array}{c}n=87 \\
\$ 1487.64 \\
{[3202.58]}\end{array}$ & $\begin{array}{c}n=4130 \\
\$ 2577.14 \\
{[3636.34]}\end{array}$ & $\begin{array}{c}n=92 \\
\$ 3740.24 \\
{[6407.14]}\end{array}$ \\
\hline $\begin{array}{l}\text { I Procedure } \\
\text { Inpatient }\end{array}$ & $\begin{array}{c}n=1089 * \\
\$ 9058.13 \\
{[18,134.05]}\end{array}$ & $\begin{array}{c}n=1157 \\
\$ 29,988.03 \\
{[26,655.8 I]}\end{array}$ & $\begin{array}{c}n=1338^{*} \\
\$ 15,758.46 \\
{[29,427.67]}\end{array}$ & $\begin{array}{c}n=56 * \\
\$ 26,026.82 \\
{[35,015.8 I]}\end{array}$ \\
\hline $\begin{array}{c}2+\text { Procedures } \\
\text { Outpatient }\end{array}$ & $\begin{array}{c}n=874 \\
\$ 1704.73 \\
{[268 \mid .40]}\end{array}$ & - & $\begin{array}{c}n=534 \\
\$ 4083.74 \\
{[6162.69]}\end{array}$ & $\begin{array}{c}n=18 \\
\$ 6639.89 \\
{[9252.49]}\end{array}$ \\
\hline $\begin{array}{l}\text { 2+ Procedures } \\
\text { Both Outpatient } \\
\text { and Inpatient }\end{array}$ & $\begin{array}{c}n=3 \mid 1 * \\
\$ 12,9 \mid 4.44 \\
{[|7,76| .92]}\end{array}$ & $\begin{array}{c}n=3 \\
\$ 26,497.98 \\
{[25,317.69]}\end{array}$ & $\begin{array}{c}n=339 * \\
\$ 29,891.68 \\
{[33,608.41]}\end{array}$ & - \\
\hline $\begin{array}{c}2+\text { Procedures } \\
\text { Inpatient }\end{array}$ & $\begin{array}{c}n=138 * \\
\$ 18,475.94 \\
{[26,969.22]}\end{array}$ & $\begin{array}{c}n=7 \\
\$ 48,332.88 \\
{[39,080.67]}\end{array}$ & $\begin{array}{c}n=72 * \\
\$ 35,994.37 \\
{[51,440.86]}\end{array}$ & $\begin{array}{c}n=1 \\
\$ 16,806.26 \\
{[n / a]}\end{array}$ \\
\hline
\end{tabular}

Notes: Asterisk*: selected inpatient and combination. Both outpatient and inpatient include biopsies that occurred outside of the range of hospital day -1 to +2 , where costs were estimated to be the median cost of outpatient biopsies of the same type.

A large number of patients, 5434 (19.2\%), were observed to have lung cancer therapy with no evidence of biopsy. Zhang et al found an even higher percentage of patients $(45.7 \%)$ with a lack of identifiable biopsy within 6 months of diagnosis. ${ }^{10}$ Some patients, with a history of cancer or a first observed diagnosis on claims beyond 6 months, may have merely experienced delayed treatment. However, it is a mystery how the diagnosis of cancer was made for these patients and reflects a limitation of the data. We can provide no estimate of the costs of a lung cancer diagnosis for these patients. Further, using a 6-month time period may have limited observing some costs associated with a protracted diagnosis process.

We used a single diagnosis of lung cancer in the primary diagnosis position as evidence of lung cancer. By using only claims data, we did not have a confirmed pathological diagnosis of cancer. A single diagnosis may not be a severe limitation. Ramsey et al evaluated the sensitivity of a single medical claim with a lung cancer diagnosis, which was confirmed with the SEER registry, and reported a sensitivity of $99.4 \%$ for commercial plan members. $^{22}$

Claims were counted until the point of treatment. While we attempted to separate diagnosis and treatment claims, we may have included some costs associated with treatments if claims for diagnosis and treatments were combined. This is particularly a concern for patients with inpatient admissions. The costs presented for inpatient biopsies may be biased upwards from true costs.

This analysis also excluded patients who received multiple biopsy types, a population subset that may have more complications, limiting the scope of the analysis. With multiple biopsy types, we were unable to attribute costs and complications to a specific biopsy. We also limited the inclusion of complications to those occurring within a time window of 1 day to 3 days after the procedure. Analysis of complication rates and costs associated with multiple biopsy types in this population, longer time windows for observing complications, as well as analyses of the associations among patients' demographic characteristics, complications and costs, are subjects for further research.

\section{Conclusion}

Healthcare costs associated with the diagnosis of lung cancer are primarily driven by repeat procedures and setting (inpatient versus outpatient). In our analysis, $41.9 \%$ of diagnosed and treated lung cancer patients undergo multiple biopsies, increasing mean healthcare costs by $40-80 \%$ depending on 
procedure type. Multiple biopsies add substantially to the cost burden of lung cancer diagnosis, leaving an opportunity for technological advancements that increase accuracy and effectiveness, leading to fewer repeat biopsies. Over one-quarter of procedures were performed on an inpatient basis, leaving an opportunity for greater use of outpatient services, when medically appropriate, to substantially reduce payer costs.

\section{Ethics Approval and Informed Consent}

As the database is fully de-identified and compliant with HIPAA regulations this study was deemed exempt by the Louisiana State University Health Sciences Center - New Orleans Institutional Review Board.

\section{Acknowledgments}

Intuitive Surgical, Sunnyvale, CA, USA sponsored the study. The sponsor was involved in the study design, collection, analysis, and interpretation of data, as well as data checking of information provided in the manuscript. The abstract of this paper was presented at ISPOR May 2020 (a virtual conference) as a poster presentation with interim findings. The poster's abstract was published in Value in Health, 23 (Supplement 1, May 2020) Abstract PN137, S47. Available at: https://www.sciencedirect.com/ journal/value-in-health/vol/23/suppl/S1?page=3

\section{Author Contributions}

The authors had unrestricted access to study data and were responsible for all content and editorial decisions. All authors made a significant contribution to the work reported, whether that is in the conception, study design, execution, acquisition of data, analysis and interpretation, or in all these areas; took part in drafting, revising or critically reviewing the article; gave final approval of the version to be published; have agreed on the journal to which the article has been submitted; and agree to be accountable for all aspects of the work.

\section{Disclosure}

OW and JL are employees of Intuitive Surgical. YWC, YHK, MJS, DEO, RAC, and DGS received grants for the development of this publication from Intuitive Surgical. MJS is the principal investigator and FDA Medical Expert for the new national multicenter trial of injectable chemotherapeutic and was a consultant for product development for Auris Health. The authors received no honoraria related to the development of this publication. The authors report no other conflicts of interest in this work.

\section{References}

1. American Cancer Society. Cancer facts \& figures. Atlanta, GA; 2018. Available from: https:/www.cancer.org/research/cancer-factsstatistics/all-cancer-facts-figures/cancer-facts-figures-2018.html. Accessed December 1, 2020.

2. National Cancer Institute. Surveillance, epidemiology and end results. Available from: https://seer.cancer.gov/statfacts/html/lungb. $\mathrm{html}$. Accessed December 1, 2020.

3. Gould MK, Donington J, Lynch WR, et al. Evaluation of individuals with pulmonary nodules: when is it lung cancer? Diagnosis and management of lung cancer. 3rd ed: American College of Chest Physicians evidence-based clinical practice guidelines. Chest. 2013;143(suppl):e93s-e119s. doi:10.1378/chest.12-2351

4. NCCN Clinical Practice Guidelines in Oncology (NCCN Guidelines $^{\circledR}$ ) Non-Small Cell Lung Cancer Version 2.2019 November 21; 2018

5. Patel JN, Ersek JL, Kim ES. Lung cancer biomarkers, targeted therapies and clinical assays. Transl Lung Cancer Res. 2015;4:503-514. doi:10.3978/j.issn.2218-6751.2015.06.02

6. Hansen L. The MarketScan ${ }^{\circledR}$ databases for life sciences researchers. Ann Arbor, MI: Truven Health Analytics Inc; 2016.

7. Charlson ME, Pompei P, Ales KL, et al. A new method of classifying prognostic comorbidity in longitudinal studies: development and validation. J Chron Dis. 1987;40:373-383. doi:10.1016/00219681(87)90171-8

8. Quan H, Sundararajan V, Halfon P, et al. Coding algorithms for defining comorbidities in ICD-9-CM and ICD-10 administrative data. Med Care. 2005;43(11):1130-1139. doi:10.1097/01. mlr.0000182534.19832.83

9. Vyas KS, Davenport DL, Ferraris VA, et al. Mediastinoscopy: trends and practice patterns in the United States. South Med J. 2013;106:539-544. doi:10.1097/SMJ.0000000000000000

10. Zhang Y, Shi L, Simoff MJ, et al. Biopsy frequency and complications among lung cancer patients in the United States. Lung Cancer Manag. 2020;9(4):LMT40. doi:10.2217/lmt-2020-0022

11. Shinde R, Cao X, Kothari S. Biopsy procedures and molecular testing utilization and related costs in patients with metastatic lung cancer. $J$ Managed Care Specialty Pharm. 2016;22:1194-1203. doi:10.18553/jmcp.2016.15404

12. Wiener RS, Schwartz LM, Woloshin S, et al. Population-based risk of complications following transthoracic needle lung biopsy of a pulmonary nodule. Ann Intern Med. 2011;155:137-144. doi:10.7326/0003-4819-155-3-201108020-00003

13. Maybody M, Muallem N, Brown KT, et al. Autologous blood patch injection versus hydrogel plug in CT-guided lung biopsy: a prospective randomized trial. Radiology. 2019;290(2):547-554. doi:10.1148/radiol.2018181140

14. Heerink WJ, de Bock GH, de Jonge GJ, et al. Complication rates of CT-guided transthoracic lung biopsy: meta-analysis. Eur Radiol. 2017;27:138-148. doi:10.1007/s00330-016-4357-8

15. Memoli JSW, Nietert PJ, Silvestri GA. Meta-analysis of guided bronchoscopy for the evaluation of the pulmonary nodule. Chest. 2012;142:385-393. doi:10.1378/chest.11-1764

16. Ost DE, Ernst A, Lei X, et al. Diagnostic yield and complications of bronchoscopy for peripheral lung lesions. Results of the AQuIRE Registry. Am J Respir Crit Care Med. 2016;193:68-77.

17. Nasso G, Piancone F, Bonifazi R, et al. Prospective randomized clinical trial of the FloSeal matrix sealant in cardiac surgery. Ann Thorac Surg. 2009;88:1520-1526. doi:10.1016/j. athoracsur.2009.07.014 
18. Mariotto AB, Robin Yabroff K, Shao Y, et al. Projections of the cost of cancer care in the United States: 2010-2020. J Nat Can Instit. 2011;103:117-128. doi:10.1093/jnci/djq495

19. Yang SC, Lai WW, Su WC, et al. Estimating the lifelong health impact and financial burdens of different types of lung cancer. $B M C$ Cancer. 2013;13(1):579. doi:10.1186/1471-2407-13-579

20. Lokhandwala T, Bittoni MA, Dann RA, et al. Costs of diagnostic assessment for lung cancer: a Medicare claims assessment. Clin Lung Cancer. 2017;18:e27-e34. doi:10.1016/j.cllc.2016.07.006
21. Huo J, $\mathrm{Xu} \mathrm{Y}$, Sheu T, et al. Complication rates and downstream medical costs associated with invasive diagnostic procedures for lung abnormalities in the community setting. JAMA Intern Med. 2019;179(3):324-332. doi:10.1001/jamainternmed.2018.6277

22. Ramsey SD, Scoggins JF, Blough DK, et al. Sensitivity of administrative claims to identify incident cases of lung cancer: a comparison of 3 health plans. J Managed Care Pharm. 2009;15:659-668. doi:10.18553/jmcp.2009.15.8.659

\section{Publish your work in this journal}

ClinicoEconomics and Outcomes Research is an international, peerreviewed open-access journal focusing on Health Technology Assessment, Pharmacoeconomics and Outcomes Research in the areas of diagnosis, medical devices, and clinical, surgical and pharmacological intervention. The economic impact of health policy and health systems organization also constitute important areas of coverage. The manuscript management system is completely online and includes a very quick and fair peer-review system, which is all easy to use. Visit http://www.dovepress.com/testimonials.php to read real quotes from published authors. 